\title{
Prevalence of ESBL and MBL Producing Pseudomonas aeruginosa in a Tertiary Care Hospital in Tirunelveli, India
}

\author{
J.K. Jeyabharathi ${ }^{1 *}$ and I. Rejitha ${ }^{2}$ \\ ${ }^{1}$ Thoothukudi Government medical college hospital, Tamil Nadu, India \\ ${ }^{2}$ Tirunelveli Government medical college hospital, Tamil Nadu, India \\ *Corresponding author
}

\section{A B S T R A C T}

\begin{tabular}{|c|}
\hline Keywords \\
\hline $\begin{array}{l}\text { Pseudomonas } \\
\text { aeruginosa, ESBL, } \\
\text { MBL, Combined } \\
\text { disc test }\end{array}$ \\
\hline Article Info \\
\hline $\begin{array}{l}\text { Accepted: } \\
10 \text { March } 2018 \\
\text { Available Online: } \\
10 \text { April } 2018\end{array}$ \\
\hline
\end{tabular}

\section{Introduction}

Pseudomonas aeruginosa is a clinically troublesome gram negative pathogen that causes a wide range of opportunistic infections and nosocomial outbreaks (Senda et al., 1996). Pseudomonas aeruginosa is responsible for $10-15 \%$ of the nosocomial infections worldwide.

Pseudomonas aeruginosa is a uniquely problematic pathogen because of its natural resistance to many drug classes and its ability to acquire resistance (via mutations) against all relevant treatments. Multi-drug resistance

\begin{abstract}
The present study was done to detect Extended spectrum $\beta$ lactamase and metallo- $\beta$ lactamase producing isolates of Pseudomonas aeruginosa from various clinical samples from patients admitted in Tirunelveli Government medical college hospital. In this study we studied the prevalence of ESBL and MBL among 112 Pseudomonas aeruginosa isolates, following standard methods of isolation and identification of these bacteria from clinical materials. Out of 112 isolates of Pseudomonas aeruginosa, 32 were producing Imiped spectrum $\beta$ lactamase enzyme producing isolates, 11 isolates were resistance to producing isolates. The present study underlines the unique problem that the presence of ESBL has led to the widespread use of Imipenem which in turn led to the emergence of MBLs. Infection caused by MBL (metallo- $\beta$-lactamase) positive isolates of Pseudomonas aeruginosa is important to identify because it poses not only therapeutic problem due to broad spectrum drug resistance, but also a serious concern for infection control.
\end{abstract}

in Pseudomonas aeruginosa makes treatment of infections caused by this organism both difficult and expensive (Strateva and Yordanov, 2009).

Extended-spectrum $\beta$-lactamases (ESBLs) are enzymes that mediate resistance to extendedspectrum cephalosporins, such as cefotaxime, ceftriaxone, and ceftazidime, and the monobactam aztreonam (Jiang et al., 2006). The drug of choice for such ESBL producing Pseudomonas aeruginosa are carbapenems. However, reports of carbapenemases have been increasing in recent years (Nordmann and Poirel, 2002). 
Carbapenemases are enzymes that have the common property of hydrolyzing, at least partially, imipinem or meropenem. Class B or the metallo-enzymes (MBL) are the most clinically threatening carbapenemases because they are capable of hydrolyzing all $\beta$ lactams except aztreonem (Yong et al., 2002). Metallo beta lactamase is a binuclear zinc-dependent enzyme whose activity is susceptible to EDTA, where it is not inhibited by clavulanic acid, tazobactam, and sulbactam (Nordmann and Poirel, 2002).

The IMP and VIM genes responsible for MBL production are horizontally transferable via plasmids and can rapidly spread to other bacteria (Nordmann and Poirel, 2002; Varaiya et al., 2008). So the occurrence of MBL positive isolates in a hospital setting not only pose a therapeutic problem, but also it is a serious concern for infection control management (Pitout et al., 2005). In some countries Pseudomonas aeruginosa possessing MBL constitute nearly $20 \%$ of all nosocomial isolates, In India, published reports indicate the prevalence of MBLs to range from 7-65\% (Manoharan et al., 2010).

Hence, the present study was conducted to detect the presence of ESBL and MBL producing Pseudomonas aeruginosa among clinical isolates from Tirunelveli medical college hospital, so as to help in formulating an effective antibiotic policy and to plan a proper hospital infection control strategy to prevent the spread of these strains.

\section{Materials and Methods}

A total of 112 isolates of Pseudomonas aeruginosa were obtained from various clinical samples like pus, sputum, urine, blood, CSF, pleural fluid and aural swabs in Tirunelveli medical college hospital from January 2012 to June 2012. Pseudomonas aeruginosa isolates were identified as per the standard microbiological procedures (Collee et al., 2008).

Antimicrobial susceptibility testing was performed on Mueller hinton agar plates by Kirby-Bauer disc diffusion method according to CLSI guidelines. Following antibiotic discs were used gentamicin (GM) 10 $\mu \mathrm{g}$, amikacin

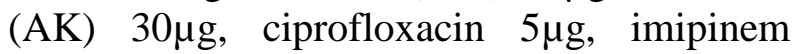
(IMP) $10 \mu \mathrm{g}$ and ceftazidime (CAZ) $30 \mu \mathrm{g}$. The zones of inhibition were interpreted as per CLSI guidelines (Clinical and Laboratory Standards Institute, 2006). The quality control strains used for the study were Escherichia coli ATCC 25922 and Pseudomonas aeruginosa ATCC 27853.

\section{Test for detection of extended spectrum beta lactamase}

All the isolates of Pseudomonas aeruginosa which showed resistance to ceftazidime were evaluated for ESBL production. Briefly, a 0.5 MacFarland's suspension of each isolate was spread on a Muller - Hinton agar (MHA) plate and ceftazidime $(30 \mu \mathrm{g})$ and ceftazidime / clavulanic acid $(30 \mu \mathrm{g} / 10 \mu \mathrm{g})$ discs were placed aseptically on the agar plate at a distance of about $15 \mathrm{~mm}$ from edge to edge and the cultures were incubated at $37^{\circ} \mathrm{C}$ overnight (Figure 1). The observation of a $\geq$ $5 \mathrm{~mm}$ increase in the zone diameter for ceftazidime with clavulanic acid compared to ceftazidime alone was considered positive (Clinical and Laboratory Standards Institute, 2006). The increase in the zone diameter was due to the inhibition of the $\beta$ lactamse by clavulanic acid.

\section{Test for detection of metallo beta lactamase}

\section{Imipenem- EDTA combined disc test (CDT)}

Next, $18.61 \mathrm{~g}$ of disodium EDTA.2H2O was dissolved in $100 \mathrm{~mL}$ of distilled water, and the 
pH was adjusted to 8.0 by sodium hydroxide $(\mathrm{NaOH})$ and autoclave to prepare a sterile 0.5 M EDTA solution to imipenem disks (10 $\mu \mathrm{g}$ imipenem). For each isolate, two imipinem $\operatorname{discs}(10 \mu \mathrm{g})$ were placed at a distance of $25 \mathrm{~mm}$ centre to centre on the surface of Mueller-Hinton agar plates inoculated with a bacterial suspension equivalent to 0.5 McFarland Standard (Figure 2). To one of the discs $5 \mu \mathrm{L}$ of EDTA solution was added. After 24 hours of incubation at $37^{\circ} \mathrm{C}$, an increase of $\geq 7 \mathrm{~mm}$ in the zone diameter of Imipenem with EDTA compared to imipenem alone was considered to be a positive test for the presence of an MBL in imipenem resistant strains (Yong et al., 2002).

\section{Results and Discussion}

In this study, out of the 112 Pseudomonas aeruginosa isolates $36(32 \%)$ were resistant to ceftazidime 32(28\%) ESBL producers and, imipinem resistance was found in $11(10 \%)$ isolates and out of which $7(6 \%)$ were MBL producers. None of the isolates showed coexistence of ESBL and MBL

The occurrence of MBL is significantly higher in Urine samples compared to other samples $(\mathrm{P}<0.05)$. Out of the 32 ESBL producers, majority of which were from pus $19(60 \%)$, followed by $6(19 \%)$ from sputum, $3(9 \%)$ from aural swab, $2(6 \%)$ from urine, one $(3 \%)$ from blood and one (3\%) from jugular catheter tip. Out of the 32 ESBL producers, 14(44\%) were from surgery ward, 4(12\%) from medicine ward, 4(12\%) from ortho ward, 4(12\%) from ENT ward, 2(6\%) from ICU, one (3\%) from peadiatrics, one $(3 \%)$ from Burns ward, one (3\%) from urology ward, one (3\%) from CM scheme (Table 1).

Out of the 112 clinical isolates of Pseudomonas aeruginosa, 11(10\%) were found to be resistant to imipinem. Of the 11 imipinem resistant Pseudomonas aeruginosa isolates $7(66 \%)$ were found to be metallo- $\beta$ - lactamase producers. Of the seven metallo- $\beta$ lactamase producers two were from pus sample in surgery ward, two were from aural swab in ENT ward, two were from urine sample in Urology ward and one is from pus from ICU ward. Out of the 112 clinical isolates of Pseudomonas aeruginosa, 58(52\%) were found to be resistant to Amikacin, 60 (54\%) were resistant to Gentamicin, 54(48\%) were resistant to ciprofloxacin, 36(32\%) were resistant to ceftazidime and $11(10 \%)$ were found to be resistant to imipinem (Table 2 and $3)$.

Pseudomonas aeruginosa infections are hard to treat due to natural resistance of the species as well as its remarkable ability of acquiring further mechanisms of resistance to multiple groups of antimicrobial agents. In Pseudomonas aeruginosa, different enzymic and mutational mechanisms can exist simultaneously conferring combined resistance to many strains. Multidrug resistance in $P$. aeruginosa makes treatment of infections caused by this organism both difficult and expensive. Improved methods for antimicrobial susceptibility testing are needed, including detection of emerging strains producing ESBLs and MBLs (Strateva and Yordanov, 2009). With increasing isolation of ESBL producing isolates in the hospital setting necessitating the use of carbapenems, the problem of MBL production is also increasing (Manoharan et al., 2010).

Our study showed that out of 112 Pseudomonas aeruginosa isolates, 32(28\%) were ESBL producers, which was higher than $22.22 \%$ ESBL producing isolates reported by (Pesattiwar and Peerapur, 2011) and 20.27\% by (Aggarwal et al., 2008). Majority of the ESBL producers were from surgery ward $(44 \%)$, this may be because majority of the isolates $(39 \%)$ were collected from surgery ward and major ESBL producers are from pus and wound swab (60\%). 
Table.1 Sample wise distribution

\begin{tabular}{|l|l|l|l|l|l|}
\hline NO & SPECIMIEN & $\begin{array}{l}\text { TOTAL } \\
\text { NO }(\%) \\
n=112\end{array}$ & $\begin{array}{l}\text { ESBL } \\
\text { NO }(\%) \\
n=32\end{array}$ & $\begin{array}{l}\text { IMIP REST } \\
\text { NO } \%) \\
n=11\end{array}$ & $\begin{array}{l}\text { MIBL } \\
\text { NO }(\%) \\
\text { n=7 }\end{array}$ \\
\hline $\mathbf{1}$ & Pus & $67(60)$ & $19(60)$ & $4(36)$ & $3(43)$ \\
\hline $\mathbf{2}$ & Sputum & $17(15)$ & $6(19)$ & - & - \\
\hline $\mathbf{3}$ & Urine & $8(7)$ & $2(6)$ & $3(28)$ & $2(28.5)$ \\
\hline $\mathbf{4}$ & Aural swab & $14(12.5)$ & $3(9)$ & $4(36)$ & $2(28.5)$ \\
\hline $\mathbf{5}$ & Blood & $3(2.5)$ & $1(3)$ & - & - \\
\hline $\mathbf{6}$ & Pleural fluid & $1(1)$ & - & - & - \\
\hline $\mathbf{7}$ & CSF & $1(1)$ & - & - & - \\
\hline $\mathbf{8}$ & Jugular & $1(1)$ & $1(3)$ & - & - \\
\hline
\end{tabular}

Table.2 Ward wise distribution

\begin{tabular}{|l|l|l|l|l|l|}
\hline S NO & WARD & $\begin{array}{l}\text { SAMPLES } \\
n=112\end{array}$ & $\begin{array}{l}\text { ESBL } \\
\text { NO }(\%) \\
n=32\end{array}$ & $\begin{array}{l}\text { IMP RES } \\
\text { NO }(\%) \\
n=11\end{array}$ & $\begin{array}{l}\text { MBL } \\
\text { NO }(\%) \\
n=7\end{array}$ \\
\hline 1 & Medicine & $15(13 \%)$ & $4(12.5)$ & - & - \\
\hline 2 & Surgery & $44(39 \%)$ & $14(44)$ & $3(27)$ & $2(28.5)$ \\
\hline 3 & Orthopaedics & $9(8 \%)$ & $4(12.5)$ & - & - \\
\hline 4 & $\begin{array}{l}\text { Obstetrics and } \\
\text { Gynaecology }\end{array}$ & $2(2 \%)$ & - & - & - \\
\hline 5 & Peadiatrics & $2(2 \%)$ & $1(3)$ & - & - \\
\hline 6 & ENT & $16(14 \%)$ & $4(12.5)$ & $4(36)$ & $2(285)$ \\
\hline 7 & ICU & $12(11 \%)$ & $2(6.5)$ & $1(12)$ & $1(14.5)$ \\
\hline 8 & Burns & $4(3 \%)$ & $1(3)$ & - & - \\
\hline 9 & Skin & $4(3 \%)$ & - & - & - \\
\hline 10 & CM Scheme & $2(2 \%)$ & $1(3)$ & - & - \\
\hline 11 & Urology & $2(2 \%)$ & $1(3)$ & $3(27)$ & $2(28.5)$ \\
\hline
\end{tabular}

Table.3 Antibiotic susceptibility pattern

\begin{tabular}{|l|l|l|l|}
\hline S NO & ANTIBIOTIC & \multicolumn{2}{|l|}{ RESISTANT ISOLATES } \\
\cline { 3 - 4 } & & NO $\mathrm{n}=112$ & $\%$ \\
\hline $\mathbf{1}$ & Amikacin & 58 & 52 \\
\hline $\mathbf{2}$ & Gentamicin & 60 & 54 \\
\hline $\mathbf{3}$ & Ciprofloxacin & 54 & 48 \\
\hline $\mathbf{4}$ & Ceftazidime & 36 & 32 \\
\hline $\mathbf{5}$ & Imipinem & 11 & 10 \\
\hline
\end{tabular}


Fig.1

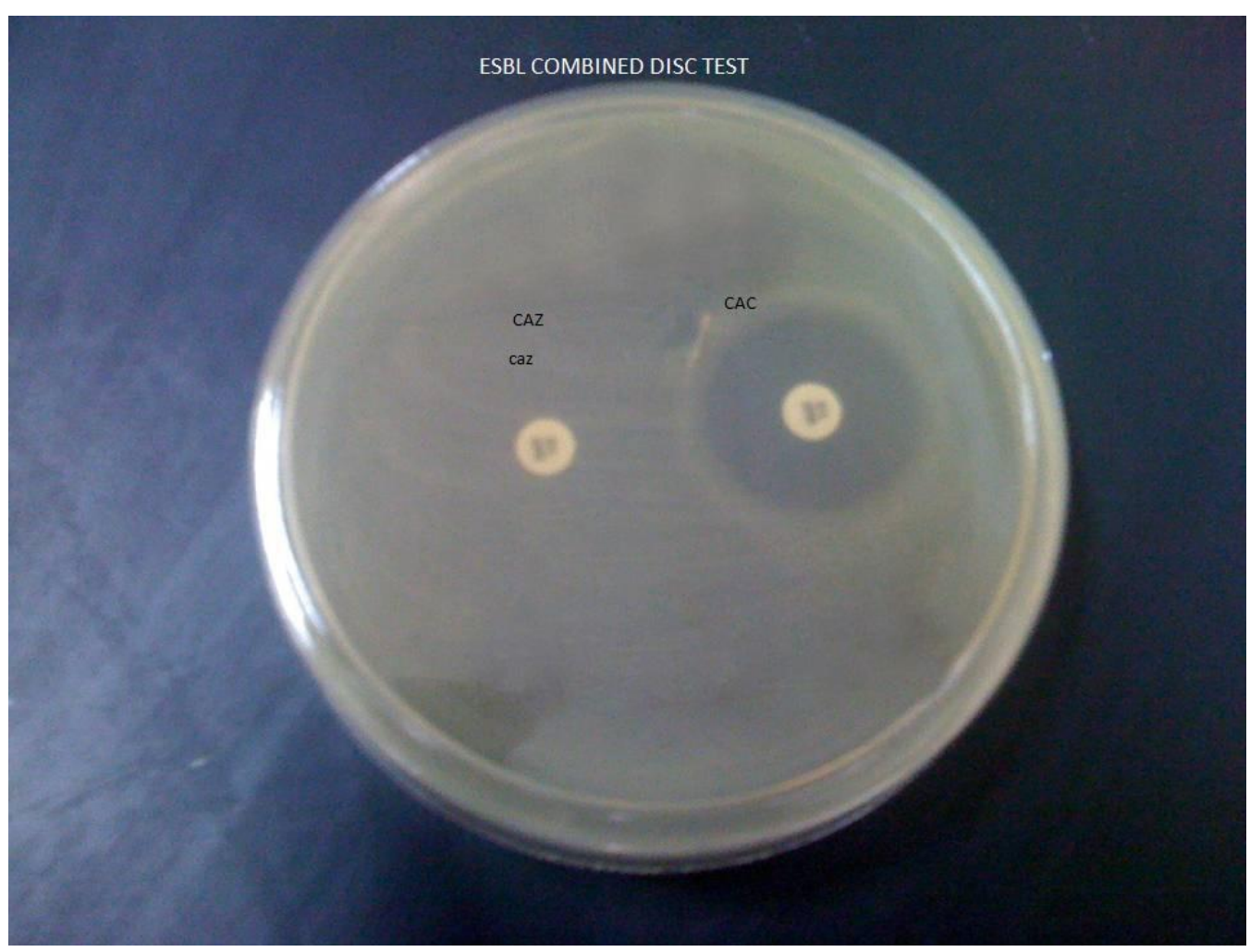

Fig.2

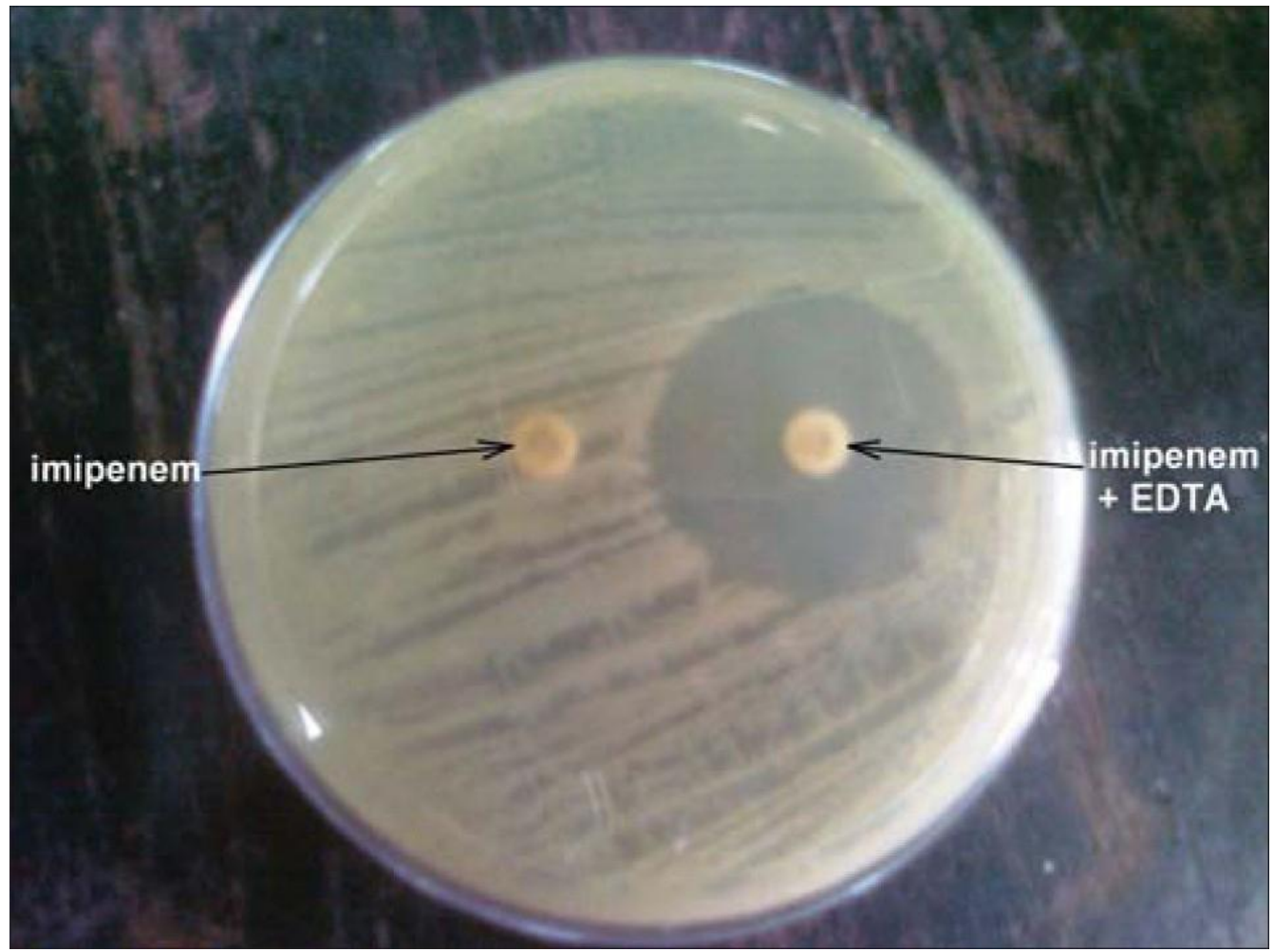


In this study, out of the 112 Pseudomonas aeruginosa isolates, 11(10\%) were imipinem resistant strains, which was less than that observed by (Varaiya et al., 2008) and (Manoharan et al., 2010) This may be due to the minimal use of carbapenems in our hospital. Of the 11 imipinem resistant strains, 7 were found to be MBL producing isolates. The likely reason for the resistance in remaining isolates may be due to other mechanisms like upregulation of an active efflux system ${ }^{13}$ or diminished expression of outer membrane protein (Buscher et al., 1987).

In the present study, the prevalence of Metallo-beta-lactamase producing Pseudomonas aeruginosa was found to be $6 \%$, which is similar to the $5 \%$ prevalence of Metallo-beta-lactamase producing Pseudomonas aeruginosa was observed and reported by (Chaudari et al., 2011) and (Ibukan et al., 2007).

In the present study, there is an increased resistance to antibiotics like Amikacin 52\%, gentamicin 54\%, ciprofloxacin $48 \%$ and ceftazidime $32 \%$. A decreased susceptibility of Pseudomonas aeruginosa to commonly used antibiotics have already been noted by previous researchers (Aggarwal et al., 2008; Jaykumar and Appalraju, 2007; Arya et al., 2005). The emergence of multidrug resistant bacteria is threatening the effectiveness of many antimicrobial agents which increases the hospital stay of the patient, thus leading to an increased economic burden on them (Peshattiwar and Peerapur, 2011).

In recent years $\mathrm{MBL}$ genes were found to be spread from Pseudomonas aeruginosa to members of Enterobacteriaceae family (Behera et al., 2008). The genes encoding IMP, VIM, SIM, GIM-1 and SPM-1 are transferable MBLs (Walsh et al., 2005). In the absence of novel agents for the treatment of infections caused by multidrug-resistant Pseudomonas aeruginosa in the near future, the spread of MBL producers may lead to treatment failures with increased morbidity and mortality. Since these organisms carry multi drug resistance genes, the only viable option that remains is potentially toxic polymyxin $\mathrm{B}$ and colistin. The early detection of MBL producers may avoid future spread of these multi drug resistant isolates (Pitout et al., 2005).

Detection of MBL producing isolates by PCR is expensive, requires specialized technicians and instruments, and more importantly, is able to detect only previously described MBL-encoding genes (Picão et al., 2008). The development of simple screening tests to detect acquired MBL production is a crucial step towards large scale monitoring of these emerging resistant determinants (Manoharan et al., 2010). Several phenotypic methods are available for the detection of MBL producing bacteria. All of these methods are based on the ability of metal chelators, such as EDTA and thiol-based compounds, to inhibit the activity of MBLs. There are conflicting reports regarding the performance of MBL E test in the literature. MBL E - Test has been reported to be insensitive to detect carbapenem sensitive MBL carrying organisms.

The combined disk test using EDTA with imipenem is simple to perform and interpret and can be easily introduced into the workflow of a clinical laboratory. This test has been used in several studies where it produced excellent sensitivity and specificity for detecting MBL-producing $P$. aeruginosa strains (Saderi et al., 2010). The detection of ESBLs and MBLs must be followed upon a routine basis in the laboratory, as it will ensure optimal patient care and the timely introduction of appropriate infection control procedures. 


\section{References}

Aggarwal R, Chaudhari U, Bala K. Detection of extended - spectrum $\beta$ lactamases in Pseudomonas aeruginosa. Indian $\mathbf{J}$ Pathol Microbiol 2008; 51: 222-24.

Arya M, Arya P, Biswas D, Prasad R. The antimicrobial susceptibility pattern of the bacterial isolates from postoperative wound infections. Indian $\mathbf{J}$ Pathol Microbiol 2005; 48: 266-69.

Behera B., Mathur P., Das A., Kapil A., Sharma V. An evaluation of four different phenotypic techniques for detecting the metallo- $\beta$-lactamases producing Pseudomonas aeruginosa. Indian J Medical Microbiology 2008; 26: 233-37.

Buscher KH, Cullmann W, Dick W. Opferkwich W. Imipenem resistance in Pseudomonas aeruginosa resulting from diminished expression of an outer membrane protein. Antimicrob Agents Chemother 1987; 31: 703-8.

Chaudari MS, Javadekar TB, Ninama G, Pandya N, Damor J. A study of Metallo-beta-lactamase producing Pseudomonas aeruginosa in clinical samples os S.S.G hospital. Nat J Med Res 2011; 1:60-63.

Clinical and Laboratory Standards Institute. Performance standards for antimicrobial disk tests; Approved Standards, 9th ed. CLSI Document M2-A9, Vol. 26 No.1 Wayne PA 2006.

Collee JG, Fraser AG, Marmion BP, Simmons A. Mackie \& McCartney Practical Medical microbiology. Govan JRW. Pseudomonas, Stenotrophomonas, Burkholderia. $14^{\text {th }}$ edition. Churchill living stone. Reed Elsevier India Private limited, New Delhi 2008: 413-424.

Ibukun A, Tochukwu N, Tolu O. Occurrence of ESBL and MBL in clinical isolates of Pseudomonas aeruginosa From Lagos,
Nigeria. Journal of American Science 2007; 3: 81-85.

Jaykumar S, and Appalraju B. The prevalence of multi and pan drug resistant Pseudomonas aeruginosa with respect to ESBL and MBL in a tertiary care hospital. Indian $\mathrm{J}$ Pathol Microbiol 2007; 50: 922-25.

Jiang X, Zhang Z, Li M, Zhou D, Ruan F and $\mathrm{Lu}$ Y. Detection of Extended-spectrum $\beta$-Lactamases in clinical isolates of Pseudomonas aeruginosa. Antimicrob Agents Chemother 2006; 50: 2990-95.

Manoharan A, Chatterjee S, Mathai D. The SARI study group. Detection and characterization of metallo beta lactamases produced by Pseudomonas aeruginosa. Indian $\mathrm{J}$ Med Microbial 2010; 28: 241-44.

Nordmann P, and Poirel L. Emerging carbapenemases in gram negative aerobes. Clin Microbiol Infect 2002; 8:321-331.

Peshattiwar PD, and Peerapur BV. ESBL and MBL mediated resistance in Pseudomonas aeruginosa: An emerging threat to clinical therapeutics. J Clin Diag Research 2011; 5: 1552-1554.

Picão R C., Andrade S S., Nicoletti A G, Campana E H. Metallo- $\beta$-Lactamase detection: Comparative evaluation of double-disk synergy versus combined disk tests for IMP-, GIM-, SIM-, or VIM- producing isolates. $\mathbf{J}$ Clin Microbiol 2008; 46:2028-37.

Pitout JDD, Gregson DB, Poirel L et al., Detection of Pseudomonas aeruginosa producing metallo-beta-lactamases in a large centralized laboratory. J Clin Microbiol 2005; 43:3129-3135.

Saderi H, Lotfalipour H, Owlia P, Salimi H. Detection of Metallo- $\beta$-Lactamase producing Pseudomonas aeruginosa isolated from burns patient in Tehran, Iran. Lab med 2010; 41:609-612. 
Senda K, Arakawa Y, Nakashima K, Ito H, Ichiyama $\mathrm{S}$, Shimokata $\mathrm{K}$ et al., Multifocal outbreaks of metallo- $\beta$ lactamase- producing Pseudomonas aeruginosa resistant to broad-spectrum $\beta$-lactams, including carbapenems. Antimicrob. Agents Chemother 1996; 40: 349-353.

Strateva T and Yordanov D. Pseudomonas aeruginosa - a phenomenon of bacterial resistance. J Med Microbiol 2009; 58: 1133-1148.

Varaiya A, Kulkarni N, Kulkarni M et al., The incidence of metallo beta lactamase producing Pseudomonas aeruginosa among ICU patients. Indian $\mathrm{J}$ Med Res 2008; 127: 398-402.

Walsh TR, Toleman MA, Poirel L Nordmann P. Metallo- $\beta$-lactamases: the quiet before the storm? Clinical Microbiology Reviews Apr 2005; 306-25.

Yong D, Lee K, Yum JH et al., ImipenemEDTA disk method for differentiation of metallo- $\beta$-lactamase producing clinical isolates of Pseudomonas spp. and Acinetobacter spp. J Clin Microbiol 2002; 40:3798-801.

\section{How to cite this article:}

Jeyabharathi, J.K. and Rejitha, I. 2018. Prevalence of ESBL and MBL Producing Pseudomonas aeruginosa in a Tertiary Care Hospital in Tirunelveli. Int.J.Curr.Microbiol.App.Sci. 7(04): 946953. doi: https://doi.org/10.20546/ijcmas.2018.704.100 